\title{
Turismo, transporte e integración: un análisis desde la conectividad y las movilidades
}

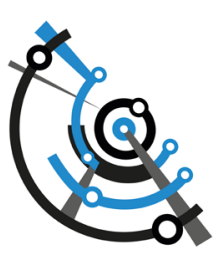

Bárbara Catalano

Instituto de Investigaciones Gino Germani, Argentina. https://orcid.org/o000-0002-7565-8451

Recibido: 7 de febrero de 2020. Aceptado: 30 de junio de 2020.

\begin{abstract}
Resumen
Partiendo del supuesto del turismo como un factor de integración a partir discursos de organismos nacionales e internacionales, es que se efectúa un desarrollo conceptual sobre el transporte, como un elemento inherente a la actividad turística y una lente a través de la cual sería posible elucidar la integración. El objetivo de este trabajo es analizar la integración en términos de conectividad y movilidad, tomando como unidad de análisis el transporte, en la escala nacional y local. Para ello, se esbozan breves nociones conceptuales sobre el transporte y su relación con el turismo, sobre todo desde los orígenes del turismo organizado a nivel internacional y en Argentina. En una escala nacional se expone la forma que presenta la trama de transportes al interior del territorio nacional para comprender el diagrama radial y las conectividades que plantean los principales sistemas de transporte turístico. En un nivel microsocial, se desarrolla un estudio de caso analizando las movilidades e integración que se despliegan a través de las prácticas de movimiento de los turistas en el destino Ciudad de Buenos Aires.
\end{abstract}

Palabras Clave: Conectividad. Integración. Movilidades. Turismo. Transporte.

\section{Tourism, transport and integration: an analysis from connectivity and mobility}

\begin{abstract}
This paper is based on the supposition by international organizations that tourism is a cause of integration. Therefore, it is explained conceptual and analytical notions of transport, as a main element of tourism and a lens through it is possible to elucidate integration. The objective of this work is to analyze integration in terms of connectivity and mobility, choosing transport as a unit of analysis, at the national and local level. Consequently, a brief conceptual notions about transport and its relationship with tourism are outlined, especially from the origins of organized tourism, internationally and in Argentina. For one hand, it is presented the accessibility by transport network
\end{abstract}


in order to understand the radial diagram of the main tourist transport systems at a national level. For the other hand, a case study is carried out, analyzing the mobility and integration which that are deployed through the social practices of tourists in the City of Buenos Aires destination.

Keywords: Accessibility. Integration. Mobilities Tourism. Transport.

Palavras Chave: Conectividade. Integração. Mobilidades. Turismo. Transporte.

\section{Introducción}

Partiendo de la asunción de que el turismo es un factor de integración entre los pueblos, en particular entre sociedades emisoras y receptoras, en este trabajo se efectúa una descripción sobre la relación entre transporte y turismo en los últimos años en Argentina. Consecuentemente se analizan los niveles de integración que se producen a través de las prácticas de los turistas en un destino específico, ciudad de Buenos Aires. De la misma forma en la que se caracteriza al turismo como un fenómeno global y una práctica social es que se utilizará ese esquema multiescalar para analizar al transporte como un indicador de integración. Se aborda, al transporte como un atributo y un proceso territorial con escalas espaciales diferenciales, poniendo foco, además en la articulación de las movilidades en torno a un sistema de circulación, atendiendo a niveles espaciales que van desde lo local a lo global (Blanco, 2010).

Cuando se piensa en la integración a través del turismo se precisa comprender que puede abarcar múltiples escalas. Considerando los regímenes de movilidades (Glick Schiller y Salazar, 2013) y los flujos turísticos a nivel global, o bien las interacciones entre turistas y residentes en un nivel micro-social (Salazar, 2006; Smith, 1989). De la misma forma se debe atender las particularidades que entrañan las políticas públicas a nivel regional en determinados bloques de integración como puede ser el Mercosur o bien la Unión Europea (Catalano, 2017). En esa línea, se habla de integración pero bajo diversos enfoques teóricos, conceptuales y metodológicos, por lo que deviene necesario considerar las escalas, local, nacional y regional para comprender el territorio, por un lado y las interacciones, como productoras de ese territorio y espacio social, por otro.

El enfoque teórico que se priorizará es el de la sociología del turismo y de las movilidades, y el modo de abordaje se nutre de múltiples técnicas considerando la complejidad del fenómeno estudiado y los niveles de análisis. Se usan fuentes secundarias para arribar a un diagrama de conectividad del territorio nacional, por un lado y por otro se utilizan fuentes primarias producto de un trabajo de campo basado en entrevistas semi-estructuradas a turistas regionales en la ciudad de Buenos Aires ${ }^{1}$.

Cabe destacar que el presente trabajo es parte de una investigación mayor en donde se analizó al turismo y su articulación con los procesos de integración en diversos niveles, por lo que en este artículo se expondrá un recorte de un tema mayor, profundizando sobre el transporte y el turismo en particular. Dadas los numerosos abordajes y conceptualizaciones que emergen sobre el turismo y transporte, en este caso se realizará un análisis del estado de la cuestión en Argentina, en los últimos años y se llevará a cabo un microanálisis de la movilidad turística en Buenos Aires para comprender la integración o no de los diversos desplazamientos de los visitantes de la ciudad. Para ello se comienza exponiendo los supuestos desde donde emerge el principal interrogante de este trabajo: ¿en qué medida el turismo es un factor de integración? Considerando 
por un lado, la integración en términos de integración física a través de los diversos sistemas de transporte, y por otro, la integración social en términos de interacciones entre turistas y residentes.

\section{Discursos dominantes: el turismo como un factor de integración}

El turismo es un fenómeno complejo, multidimensional y pasible de ser abordado de diversas ciencias y disciplinas. En la práctica, desde los organismos nacionales e internacionales se lo considera como una actividad económica generadora de ingresos e incluso como una salida a las crisis que padecen los países en desarrollos. El caso de algunos de los destinos del Caribe es un claro ejemplo de ello (Cordero Ulate, 2006). En esa línea, también es factible mencionar los argumentos que plantean los sectores empresariales involucrados, tales como que el turismo es una industria sin chimeneas o que es una actividad reactivadora de otras actividades económicas, dada la transversalidad que lo caracteriza. Esos argumentos están asociados al efecto multiplicador que se produce a partir de los ingresos por turismo y que representan un alcance mucho mayor que otras actividades tradicionales (Vellas, 2004; Ventura-Dias, 2011).

Dentro de los discursos que emanan sobre la actividad turística, además de que representa un gran impulso para las economías regionales y para las sociedades de destino, se destaca aquel relacionado al empleo, especialmente a la capacidad del turismo en generar puestos de trabajo (Oliva y Schejter, 2006). Ello no es meramente una declaración sino que tiene su asiento empírico en determinados casos de estudio puntuales. No obstante existen ciertas posiciones críticas que exigen un abordaje profundo sobre esos discursos legitimadores del turismo, ya que no se puede reproducir el mismo efecto en todos los destinos, porque se entraría en un terreno de poca rigurosidad científica (Fernández Miranda, 2011). Cabe mencionar como ejemplo el caso de los trabajadores de las agencias de turismo en Argentina en el que en un periodo de supuesta prosperidad de la actividad, según un estudio de caso, se destaca que los trabajadores de ese sector se encuentran en condiciones de informalidad y precariedad en relación a los salarios y las jornadas de trabajo (Tottino, 2015).

Siguiendo la línea de los discursos legitimadores en relación al turismo también existen supuestos en los que se sostienen políticas presentes sobre el turismo como un factor de unión e integración entre los pueblos. Esta idea sobre el turismo como vector de unión radica en la construcción de significados y legitimidad sobre concebir al turismo como un inductor del intercambio de ideas. Esos argumentos se desprenden de organismos tales como la OMT o UNESCO ${ }^{2}$, donde se sitúa al turismo como herramienta de paz ya que los flujos turísticos constituirían la posibilidad de construir y consolidar nuevas relaciones entre las personas, como también una solidaridad socioeconómica, un encuentro entre los pueblos y un instrumento de diálogo entre las civilizaciones (UNWTO y UNESCO, 2015).

A pesar de los discursos dominantes, es notable destacar las posiciones que ponen en cuestión los supuestos beneficios del turismo y que aducen que cada vez hay menos contacto y menos encuentros entre turistas y residentes, lo que lejos de facilitar encuentros, la industria turística pone barreras entre turistas y residentes con el fin de maximizar beneficios (O Moufakkir y Kelly, 2010:17). Es a partir de estos discursos legitimadores que surgen el interés y la necesidad de desenmascarar, en qué medida el turismo es un 
factor de integración, tomando como unidades de análisis el transporte en términos de conectividad como factor integrador del territorio y la movilidad como impulsora de la integración social (Catalano, 2018; IIRSA, 2005; Wallingre, 2010).

Para ello, en primer lugar se esbozan nociones conceptuales y teóricas sobre transporte y turismo, como se desarrolla a continuación.

\section{Nociones sobre transporte y turismo}

Desde la literatura propia del campo del turismo el transporte aparece como un elemento indispensable y constitutivo del sistema turístico, es parte de la infraestructura y se encuentra acompañado por canales de distribución y comercialización diversos (Panosso Netto y Lohmannm Guilherme, 2012; Ramírez et al., 2013). El transporte, como uno de los elementos del sistema turístico, no solo cumple la funcionalidad del desplazamiento, condición inherente a la definición de turismo, sino que a su vez implica conectividad y movilidad al interior del destino visitado. El transporte, concebido como parte esencial de la movilidad, es el eje articulador que permite el movimiento implícito en el turismo.

Su importancia también se ancla en el análisis de la política pública, ya sea al revisar los orígenes de la política turística en Argentina, en los inicios de la década del 30 (Piglia, 2012), como también en instrumentos más recientes tales como el Plan Federal Estratégico de Turismo Sustentable 2016, por ejemplo. En aquel instrumento de política turística, el transporte representa un elemento esencial en la construcción del mapa federal de oportunidades ${ }^{3}$ donde se pone énfasis en el tramado de conectividades y los diversos corredores turísticos, potenciales y consolidados.

Asimismo, los servicios de transporte se encuentran dentro de la clasificación uniforme de las actividades inherentes al turismo, elaborada por la Organización Mundial del Turismo (OMT) y validada a nivel nacional por la Ley de Turismo de Argentina 25997. De la misma forma, en el plano local de la ciudad de Buenos Aires, la ley 600 de turismo, también determina al transporte como una de las unidades elementales de la actividad turística, estableciendo prioridades para el aparcamiento de los vehículos con fines turísticos.

Entonces, por un lado, el transporte se concibe desde los enfoques turísticos desde el desarrollo mismo de la actividad y también, dentro de la esfera pública se encuentra enlazado a la legislación que reglamenta el turismo y los diversos servicios asociados. Por otro lado, se requiere de comprender al transporte dentro de la perspectiva de la geografía del transporte como parte del territorio donde convergen, flujos, actores y relaciones sociales. A menudo, se visualiza al transporte como un elemento pasivo por los geógrafos en el contexto turístico y no como una parte integral de la actividad turística (Lew, Hall, y Williams, 2004:141). Sin embargo, el transporte, como otro equipamiento de infraestructuras, es parte de la materialidad agregada al territorio y propulsor del movimiento de personas y objetos en un espacio dado. No solo contribuye al desplazamiento de sujetos de un lugar de origen a un lugar de destino sino que también traslada materias primas y bienes con diferentes grados de elaboración en diferentes procesos productivos (Blanco, 2010:176). Las tecnologías de transporte y comunicación proporcionan las bases para la conformación de las redes y los lazos que caracterizan a las sociedades en movimiento (Blanco, 2010; Larsen, Urry, y Axhausen,

3 El mapa de oportunidades es una herramienta que permite unir un esquema conceptual de necesidades con el territorio en concreto. Fue diseñado para lograr un ordenamiento territorial planificado y una adecuada jerarquización de prioridades (PFETS). 
2006). Desde los enfoques de las movilidades, el transporte está íntimamente asociado a procesos subjetivos y a las correlaciones de actores desde escalas regionales y globales (Zunino Singh, 2017).

\title{
Orígenes del turismo organizado y transporte
}

Ahora, bien, la relación entre el transporte y el turismo no es de reciente conformación, sino que comienza a mediados del siglo XIX, cuando las nuevas tecnologías del transporte y las innovaciones en la organización social del viaje se convirtieron en los factores desencadenantes del turismo de masas.

\begin{abstract}
(...) Ejemplos de tecnologías nuevas que exhiben la importancia de la innovación organizativa son: los primeros ferrocarriles, una tecnología nueva cuyo uso potencial para el ocio y las vacaciones no advirtieron al comienzo las compañías ferroviarias; los ferrocarriles y los vapores de fines del siglo XIX, que no desarrollaron su potencial en el mercado internacional hasta que Thomas Cookno introdujo su innovación el sistema de vouchers; los vuelos en jet, para cuyo éxito pleno hizo falta la innovación de las vacaciones con alojamiento y comida incluidos, que los operadores de tours organizaban; y el Concorde, una tecnología superior pero que no se acompañó de una innovación correspondiente en la industria de los viajes. En consecuencia, es indispensable que las tecnologías del trasporte se acompañen de una trasformación organizativa para tener éxito y dominar en determinado período histórico. (Urry y Lash, 1998:340)
\end{abstract}

Tal como se ilustra en la cita, el ferrocarril fue uno de los elementos favoritos de Cook para potenciar el turismo, sobre todo por el volumen de pasajeros que podía transportar y por su benéfica fuerza de índole social (Turner y Ash, 1991:76). La intrínseca relación entre el turismo y los medios de transporte comienza con gran fuerza en Inglaterra, para luego propagarse por todo el mundo. La historia del turismo estuvo acompañada por las transformaciones acaecidas en el transporte; este último cada vez más rápido, sostenido en infraestructuras modernas y atravesado por la continua transformación tecnológica.

A su vez, el transporte emerge como uno de los abordajes sociales sobre el turismo, dentro los estudios de las movilidades, ya que es posible, por ejemplo, determinar ciertos niveles socio-económicos de la demanda en función de la tipología de transporte utilizada. Además, en Argentina, por ejemplo, la evolución y el desarrollo del turismo a lo largo de la historia, estuvo en directa relación con los medios de transporte y con las prácticas de ocio (Pastoriza y Piglia, 2012; Schluter, 2003). Tal es así, que en los orígenes del turismo en Argentina se observó una significativa asociación con el tendido del ferrocarril, manejado en sus inicios por empresas británicas, que captaron las posibilidades de explotación turística (2012:15). Los casos paradigmáticos fueron los destinos de Mar del Plata y las Sierras de Córdoba, cuyos éxitos se debieron a la conclusión de las conexiones ferroviarias además que hubo varios destinos a los que se podía llegar solamente por medio de ferrocarril (2012:16).

A su vez, existió una estrecha relación entre el turismo y el transporte autónomo reflejado en el uso del automóvil. Los inicios del automóvil en Argentina hacia principios del siglo XX estuvieron marcados por el Automóvil Club Argentino y el Touring Club Argentino, asociaciones que cumplían una función complementaria en relación al automóvil. Mientras la primera procuraba información y espacios de encuentro social para los aficionados del automóvil y buscar oportunidades para el uso recreativo de los vehículos, la segunda intervenía en la esfera pública para promover el desarrollo 
de la vialidad y el turismo en torno a la causa patriótica (Piglia, 2014:67). Tal es así que entre los inicios de siglo hasta la actualidad la estrecha relación entre los medios de transporte y el desarrollo turístico ha sido constante, ya que a pesar de las fluctuaciones, se mantienen unidas en las más híbridas formas de hacer turismo y en las más inimaginables formas de transporte.

En esa línea, la expansión del turismo estuvo asociada a la aparición del automóvil y a la mejora vial.

\begin{abstract}
El turismo en automóvil no solo multiplicó el caudal de viajeros que fluyeron a los destinos ya consagrados por el ferrocarril; también permitió el surgimiento de lugares nuevos, como los balnearios bonaerenses al norte y al sur de Mar del Plata o las localidades pequeñas de Cuyo y del Norte (Piglia, 2014:188).
\end{abstract}

Es por ello que el turismo y el transporte están vinculados no solo desde la práctica social de viajar y desplazarse de un lugar de origen a un lugar de destino, sino que también desde las diversas estructuras sociales y físicas, ya que es funcional a determinados modelos productivos, tal como fue en Inglaterra del siglo XIX o Argentina a inicios del siglo XX. En los procesos de construcción del Estado-Nación, el desarrollo del país dependía de la integración de la economía y la producción a los mercados internacionales, acentuando un modelo centro-periferia, que en cierta forma, perdura hasta la actualidad.

En los inicios del siglo XX, cuando el turismo en Argentina empieza a considerarse como un objeto de la política pública se genera un importante impulso de los flujos turísticos hacia nuevos destinos, en parte, gracias a las mejoras en las obras de rutas nacionales, progresos en la aviación civil y nacionalización del transporte fluvial (Piglia, 2012). Esta relación entre el transporte y el desarrollo turístico se manifiesta en la actualidad, por ejemplo al observar los datos de frecuencias rutas y modalidades de transporte que se utilizan en el territorio nacional, como se observará a continuación y que en cierta medida denotan diversos niveles de integración del territorio.

\title{
Conectividad e integración territorial
}

$\mathrm{Al}$ analizar el transporte en un determinado territorio, el interrogante que emerge versa sobre los medios de transporte que operan, en qué estado se encuentran las unidades y la calidad de los servicios, las frecuencias, los horarios, accesibilidad e infraestructura complementaria. En esa línea en este apartado se esbozará un breve análisis del esquema de transporte vinculado al turismo, a partir de fuentes secundarias, con el fin de ahondar hacia un entendimiento de la relación turismo-transporte, en términos de conectividad.

\section{La conectividad en la política turística}

A partir de los comienzos del siglo XXI, el sector del turismo en Argentina se convierte en una alternativa de desarrollo y política de estado para el país, aspecto que se cristaliza en la transformación de Secretaría de Turismo en Ministerio y en la sanción de la Ley Nacional de Turismo 25.997 (Schenkel y García, 2015). Junto con este impulso del turismo, desde el Estado se efectúa un diagnóstico y estado de la cuestión que se plasma, entre varios documentos, en el Plan Federal Estratégico de Turismo Sustentable (PFETS). A través de un relevamiento nacional y talleres mixtos entre el sector público, privado y académico es que se realiza un diagnóstico sobre la conectividad vinculada al turismo en Argentina, analizando sus características. Por consiguiente, se 
determina que existían destinos con potenciales turísticos, que se encontraban aislados por carecer de medios de transporte, o bien de vías de acceso en condiciones para una apta circulación, o de infraestructura necesaria para el traslado de pasajeros. Pero por otra parte, se veía en ese diagrama un gran potencial para desarrollar el turismo a través de mejoras que implicaran inversiones en infraestructura.

El esquema de conectividad que presenta el territorio nacional conduce dificultosamente a los destinos lejanos y obliga a depender de su centro focal en la ciudad Autónoma de Buenos Aires, cada vez que se persigue diseñar un recorrido interregional. El mapa con la trama de corredores y travesías, como también de circuitos marítimos, marca la búsqueda de rupturas en las deficiencias de conectividad actual, e introduce la posibilidad de abrir al país como una trama disponible donde se tienda a producir la equilibrada accesibilidad desde cada punto del territorio, permitiendo apropiarse de toda la oferta turística nacional. (SECTUR, 2005)

Por ello, a través del PFETS y de la operacionalización de las iniciativas que allí se plasmaban se intenta impulsar el turismo a través de inversiones en infraestructura tales como redes viales, aéreas, ferroviarias y marítimas.

Cabe mencionar que en la segunda actualización del PFETS, se profundiza la política turística como política de Estado y se prioriza la articulación entre el sector de transporte y el turismo, con el fin de mejorar la conectividad aérea nacional ${ }^{4}$. En el mismo instrumento de política turística se busca fortalecer la conectividad transversal a lo largo del territorio nacional, lo que se ilustra de manera contundente en el nuevo mapa de oportunidades que incorpora numerosos corredores turísticos federales y travesías con vocación ${ }^{5}$. El objetivo de este relanzamiento del plan federal era descentralizar los flujos turísticos ampliando la red de conectividades, y mejorando infraestructuras complementarias al turismo y de esta forma, conducir la planificación hacia una concepción de desarrollo turístico más integrado.

A continuación se efectúa una descripción de los principales elementos del sistema de transporte a nivel nacional a fin de comprender la trama de conectividad plasmada en el territorio nacional.

\section{Transporte terrestre y ferroviario}

El territorio nacional cuenta con una red vial de $261.700 \mathrm{~km}$, lo que implica un alcance significativo en términos de extensión geográfica en todas las direcciones. A pesar de ello, muchos caminos se encuentran en condiciones que dificultan el tránsito de vehículos, generando el aislamiento, falta de competitividad y baja accesibilidad de zonas que cuentan con potencialidad turística. Existe una importante porción de las vías que no se encuentran pavimentadas y escases de servicios en ruta. La red de transporte ferroviario presenta una trama radial, con centro en la Ciudad Autónoma de Buenos Aires, y escasos servicios en la zona sur o Patagonia. A su vez, hay una ausencia de conexiones transversales interregionales, que se observa en el sistema vial, el ferroviario y el aéreo. Desde la década de los noventa, los servicios 
semi-rápidos y expreso fueron discontinuados perdiéndose los pasajeros de larga distancia (MINTUR, 2011). Este esquema de conectividad radial deja aisladas a localidades menores, obstaculizando de ese modo la llegada de turistas a destinos que cuentan con recursos naturales y patrimoniales pero que carecen de valor turístico por estar aislados.

En cuanto al transporte ferroviario, si bien en los comienzos del turismo organizado de Argentina, la expansión de la red ferroviaria fue el elemento impulsor del turismo de masas, tal como se mencionó anteriormente, en la actualidad no es el medio de transporte que se utiliza con más frecuencia para el desplazamiento de los pasajeros de un lugar de origen a un lugar de destino. Según el informe del CECE que analiza el mercado doméstico de transporte interurbano de pasajeros en Argentina (Sánchez, 2017), es posible observar cómo en las últimas décadas, la cantidad de pasajeros que se trasladan en ferrocarril presentan una tendencia decreciente ${ }^{6}$, mientras que la cantidad de pasajeros que utilizan la vía terrestre aumenta radicalmente año tras año, debiéndose ello principalmente a la mejora en la pavimentación de las redes viales de conexión nacional ${ }^{7}$. A lo anterior se suma una política pública agresiva contra el sistema ferroviario que desencadenó en un escaso uso del ferrocarril por motivos turísticos en los últimos años (Sánchez, 2017:8). A pesar de ello, es factible observar el uso del tren en recorridos turísticos específicos, tales como el Tren a las Nubes, la Trochita, el Tren del fin del mundo, solo para mencionar algunos ejemplos de ese uso diferenciado.

Asimismo, según la encuesta de viajes y turismo de hogares ${ }^{8}$, cuando se observa la distribución de los medios de transporte del turismo nacional, según los datos del Ministerio de Turismo de la Nación, se observa que la mayoría (68\%) del turismo nacional se realiza por el medio del automóvil, mientras que en segundo lugar se encuentra el ómnibus (25\%), y en tercer lugar el avión (5\%) (MINTUR, 2015). La preferencia por el uso del automóvil, se asocia a las características y geografía del territorio, a la diversidad de lugares para visitar y a la libertad y autonomía que otorga el vehículo para el recorrido de múltiples destinos y a la escases de rutas y frecuencias ofrecidos por otros medios de transporte, como son el ómnibus y el avión.

En cuanto al sistema de transporte de larga distancia, en Argentina tiene un peso significativo, sobre todo en términos de conexión interurbana, en relación a los ingresos económicos que generan las ventas de pasajes y a su intrínseca relación con el resto de los servicios turísticos tales como la hotelería o la gastronomía (Castro y Lotitto, 2014). A su vez, analizando las frecuencias de salidas a las distintas regiones de Argentina se observa que existe una distribución relativamente equitativa entre las salidas, las provincias y las distancias entre origen y destino para el año 2015. Cabe destacar que este sector se encuentra atravesando una crisis debido a la aparición de varias compañías aéreas denominadas low cost y a la consecuente comercialización, por parte de las mismas, de rutas que antes eran realizadas exclusivamente por el transporte terrestre. A ello se le añade que se introduce un

6 En el año 1960 se trasladaron 62.498.00o personas en ferrocarril, en el año 1990, 10.891.00o y finalmente en el 2016, 774.551 (Sánchez, 2017:11).

7 La red pavimentada en 1990 era de 61 mil km, en el año 2000, de 70 mil y en 2010, de 77 mil (Sánchez, 2017)

8 La Encuesta de Viajes y Turismo de los hogares mide la evolución de los viajes realizados por los hogares argentinos residentes en los grandes aglomerados urbanos (dos tercios de la población total del país), sus características y computar aspectos socio-demográficos que permitan caracterizar a los turistas residentes. 
nuevo elemento en la oferta de transportes, lo que presiona la competitividad de los actores, generando un viraje en las formas de viajar hacia los destinos nacionales ${ }^{9}$.

Finalmente, puede destacarse que la modernización de la flota de estos servicios y unidades de transporte de larga distancia ha facilitado la integración de los mercados del trabajo, la actividad turística y las relaciones familiares dentro del sector turístico (Castro y Lotitto, 2014). No obstante, el sector presenta importantes falencias desde el punto de vista regulatorio, que exige un abordaje sistémico, con el fin de alcanzar políticas públicas integrales que contemplen la competencia existente entre los diversos medios y empresas de transporte, en particular el transporte aéreo y las rutas de cabotaje.

Cuadro 1. Salidas de micro-ómnibus de larga distancia Nacional desde la Terminal de Retiro, por región de destino. Octubre 2015. Fuente: Dirección de Estudios de Mercado y Estadística de la DNDT, SSDT, MINTUR, en base a datos suministrados por INDEC. Nota: Norte: Jujuy, Salta, Catamarca, Tucumán, Formosa y Chaco; Cuyo: La Rioja, San Juan, San Luis, Mendoza; Centro: Córdoba, Santiago del Estero, Santa Fé, La Pampa; Litoral: Misiones, Corrientes, Entre Ríos; Costa Atlántica: Mar de Ajó, Villa Gesell, Mar del Plata, Miramar, Necochea, Pinamar, San Bernardo; Interior de Buenos Aires: resto de la Provincia de Buenos Aire; Sur: Neuquén, Río Negro, Chubut, Santa Cruz.

\begin{tabular}{|l|c|c|c|c|}
\hline Región de destino & Octubre 2015 & $\begin{array}{c}\text { Variación } \\
\text { interanual (\%) }\end{array}$ & $\begin{array}{c}\text { Acumulado } \\
\mathbf{2 0 1 5}\end{array}$ & $\begin{array}{c}\text { Variación } \\
\text { interanual } \\
\text { acumulada (\%) }\end{array}$ \\
\hline TOTAL & 20.350 & $-2,2$ & 205.229 & $-0,9$ \\
\hline Centro & 4.804 & $-5,6$ & 48.567 & $-0,9$ \\
\hline Interior de Buenos Aires & 3.775 & $-0,9$ & 34.810 & $-1,7$ \\
\hline Litoral & 3.468 & 3,5 & 33.838 & 2,3 \\
\hline Norte & 3.363 & 0,1 & 34.008 & -1 \\
\hline Costa Atlántica & 2.751 & $-5,5$ & 31.115 & $-2,4$ \\
\hline Sur & 1.195 & $-3,6$ & 12.454 & $-1,9$ \\
\hline Cuyo & 994 & $-5,4$ & 10.437 & $-2,3$ \\
\hline
\end{tabular}

9 Diario Perfil, 24 de enero de 2018, Empresas de micros denuncian una potencial crisis por las low-cost, disponible en https://www.perfil.com/noticias/economia/empresas-de-micros-denuncian-una-potencial-crisis-por-las-lowcost.phtml 


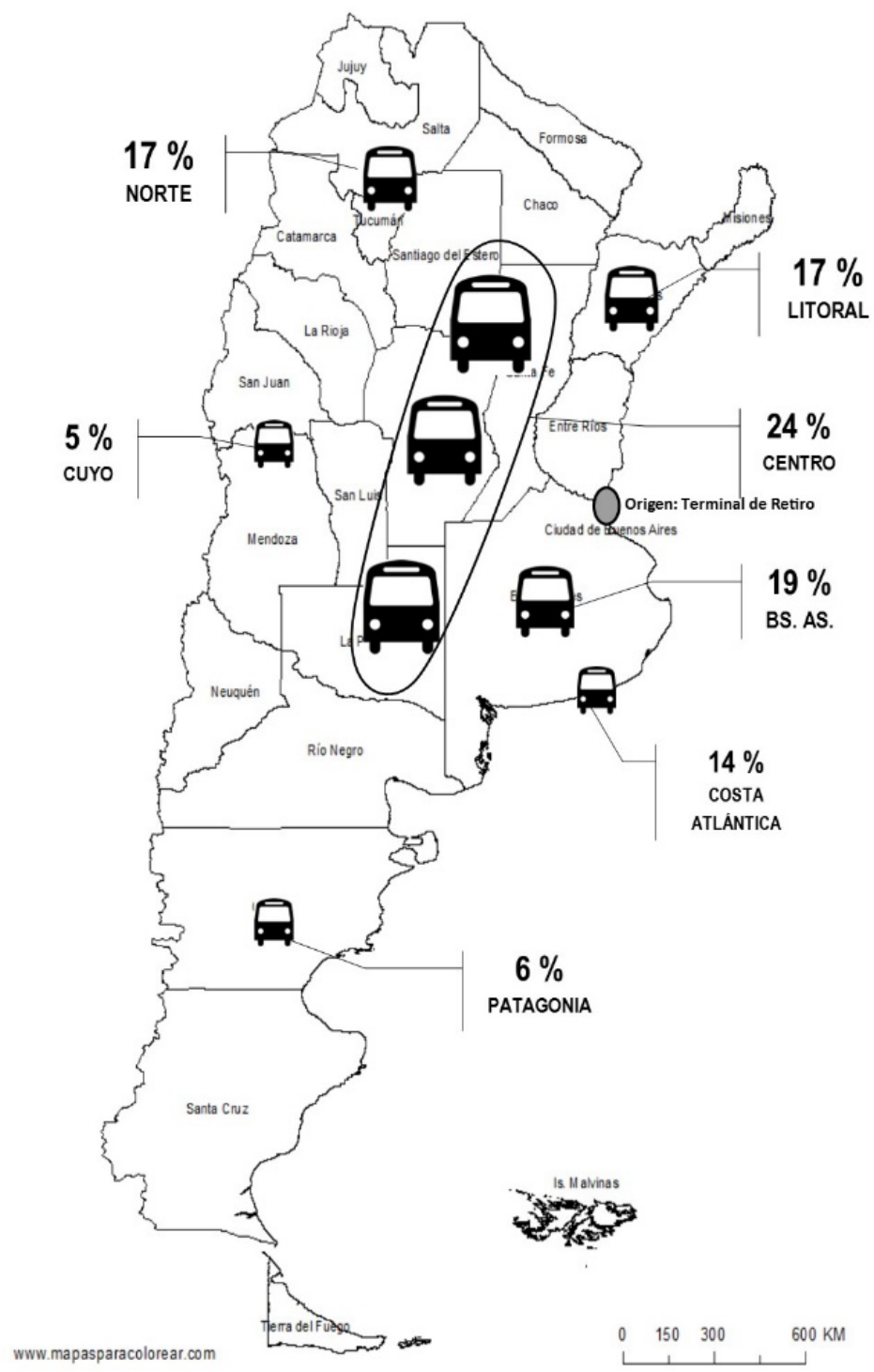

Figura 1. Mapa de distribución de salidas de micro-ómnibus de larga distancia nacional desde la Terminal de Retiro, por región de destino, 2015. Fuente: Elaboración propia en base a Cuadro 1.

\section{Transporte aéreo}

El turismo y el transporte aéreo son inseparables cuando se habla de viajes transoceánicos, pero en el caso de desplazamientos dentro de un mismo territorio se podría esgrimir que su importancia es relativa. No obstante, dadas las características geográficas de Argentina, su vasta extensión y sobre todo las distancias considerables que separan a sus principales atractivos turísticos, es que los vuelos de cabotaje devienen en un elemento inseparable para analizar la integración y la conectividad. Tal es así que desde Iguazú a El Calafate hay $4028 \mathrm{~km}$ de distancia por vía terrestre. Las dos ciudades son cabecera de los Parques Nacionales más visitados del país (Parque Nacional Los Glaciares y Parque Nacional Iguazú).

En los cuadros siguientes se esboza brevemente un esquema de conectividad aérea nacional que permite comprender las principales rutas y los destinos conectados. 
Cuadro 2. Distribución de frecuencias aéreas, vuelos de cabotaje por destino. Años 2012-2015. Fuente: elaboración propia en base a MINTUR.

\begin{tabular}{|l|c|c|c|c|}
\hline \multirow{2}{*}{} & \multicolumn{5}{|c|}{$\begin{array}{c}\text { Frecuencias aéreas de vuelos de cabotaje, distribución } \\
\text { porcentual por región de destino }\end{array}$} \\
\cline { 2 - 5 } & $\mathbf{2 0 1 5}$ & $\mathbf{2 0 1 4}$ & $\mathbf{2 0 1 3}$ & $\mathbf{2 0 1 2}$ \\
\hline CABA & 44,5 & 44,1 & 43,2 & 42,6 \\
\hline Patagonia & 20 & 21,3 & 22 & 20,3 \\
\hline Norte & 9,6 & 8,3 & 8,4 & 8,6 \\
\hline Litoral & 8,4 & 9,2 & 9 & 10,1 \\
\hline Buenos Aires & 3,4 & 2,8 & 3,4 & 3,2 \\
\hline Cuyo & 7,5 & 7,7 & 7,9 & 8,2 \\
\hline Córdoba & 6,5 & 6,5 & 6,1 & 7,1 \\
\hline
\end{tabular}

Se observa que Buenos Aires, es la escala obligada para muchos tramos internos dado que las frecuencias aéreas se encuentran centralizadas allí. Si bien en los últimos años se han incorporado tramos que unen Bariloche, Salta, Mendoza e Iguazú, la mayor proporción de los destinos volados requieren escala en CABA, convirtiéndose en un punto de confluencia. De la misma forma, la mayoría de los vuelos internacionales arriban a CABA, punto de conexión con el resto de los destinos de Argentina y también de otros nodos receptivos dentro de la región.

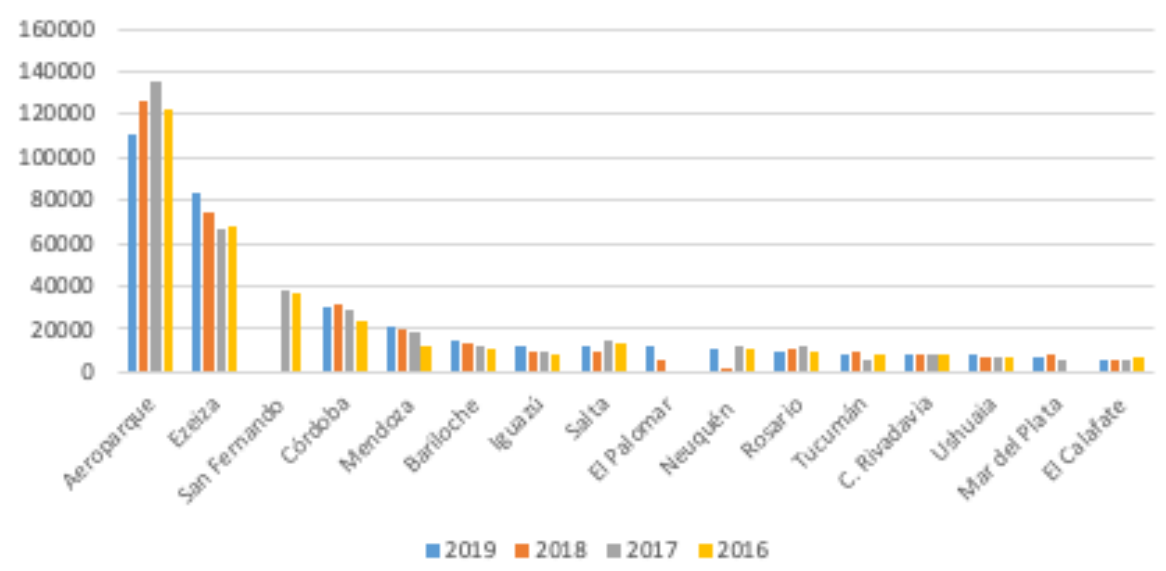

Figura 2. Principales aeropuertos del país en término de su número de movimientos (despegues + aterrizajes) 2016-2019. Fuente: ANAC.

A continuación se exponen las rutas que operan las principales ciudades turísticas del país: Buenos Aires, Mar del Plata, Iguazú, Mendoza, Córdoba, Bariloche, El Calafate, Ushuaia. La selección de dichas ciudades se efectúa a partir de los sitios donde están emplazados los parques nacionales más visitados del país y las ciudades con mayor oferta de plazas hoteleras, según el Anuarios Estadístico de Turismo 2015. La figura siguiente intenta ilustrar el diagrama radial que presenta la conectividad aérea en el territorio nacional, con una intensa centralización en la ciudad de Buenos Aires. Además es factible observar la dificultad que implica la ausencia de ciertas rutas que unirían destinos turísticos de relevancia, tales como Calafate -Iguazú, considerando que son los destinos turísticos donde se emplazan los parques nacionales más visitados de Argentina (Parque Nacional Los Glaciares y Parque Nacional Iguazú); o también la ruta Ushuaia - Bariloche, solo para mencionar algunos ejemplos. 


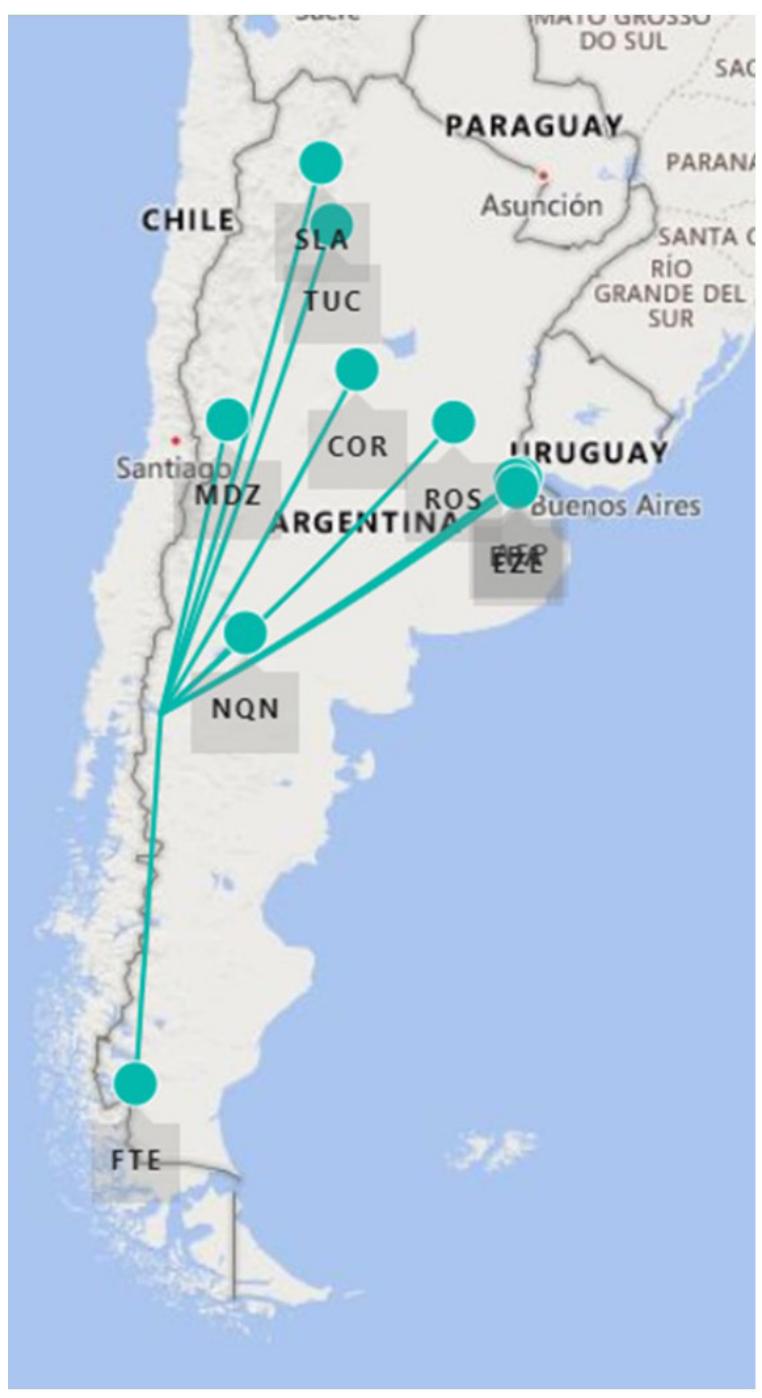

Figura 3. Rutas aéreas de cabotaje desde el Aeropuerto de Bariloche (BRC). Año 2019. Fuente ANAC.

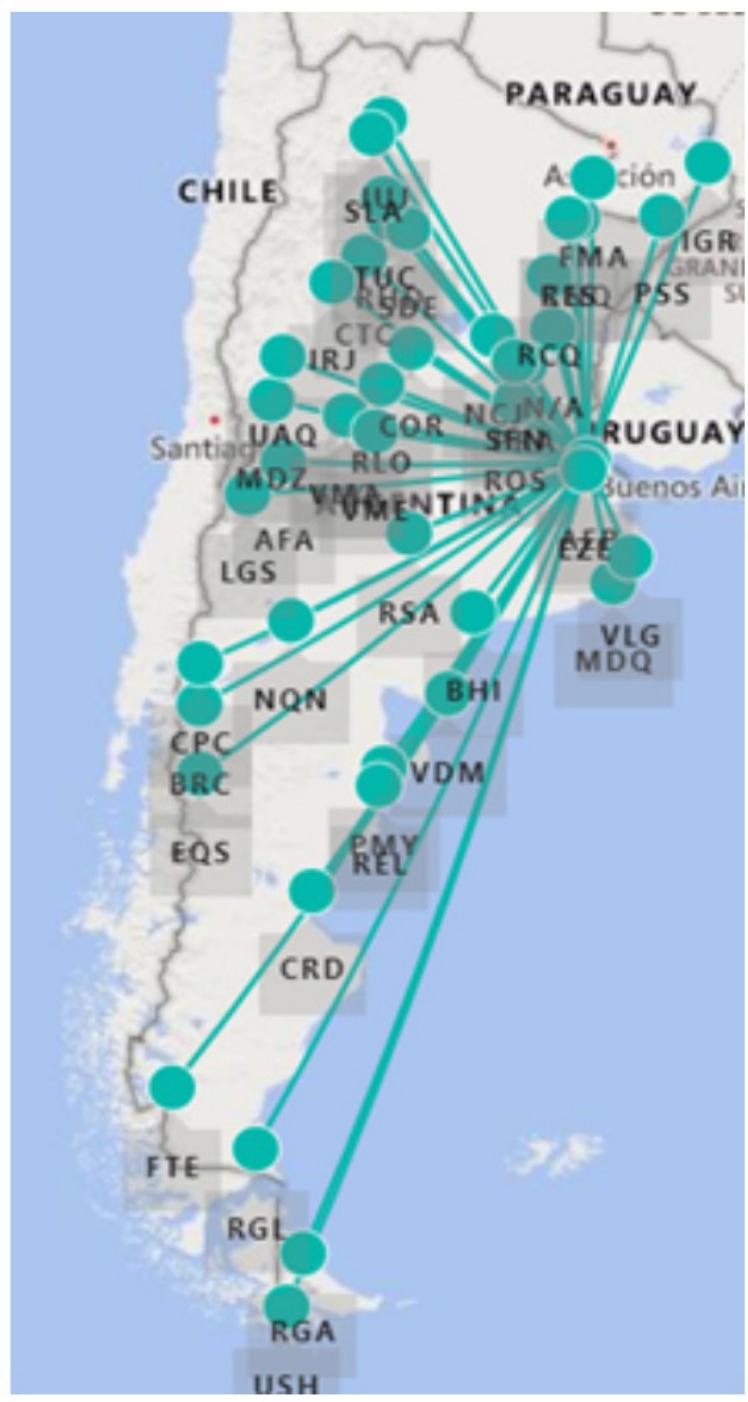

Figura 4. Rutas aéreas de cabotaje desde el Aeropuerto de Cabotaje de Buenos Aires (AEP). Año 2019. Fuente ANAC. 


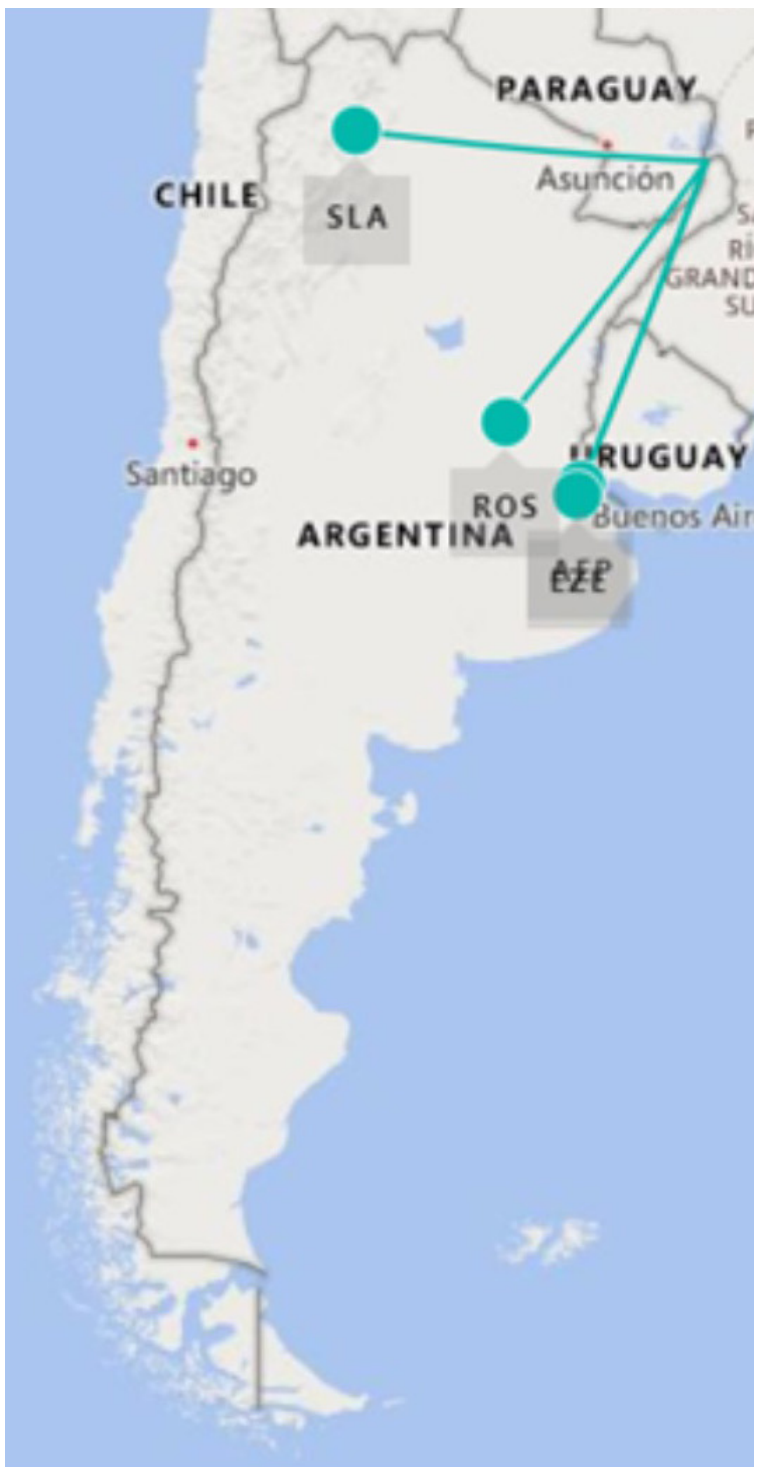

Figura 5. Rutas aéreas de cabotaje desde el Aeropuerto de Iguazú (IGR). Año 2019. Fuente ANAC.

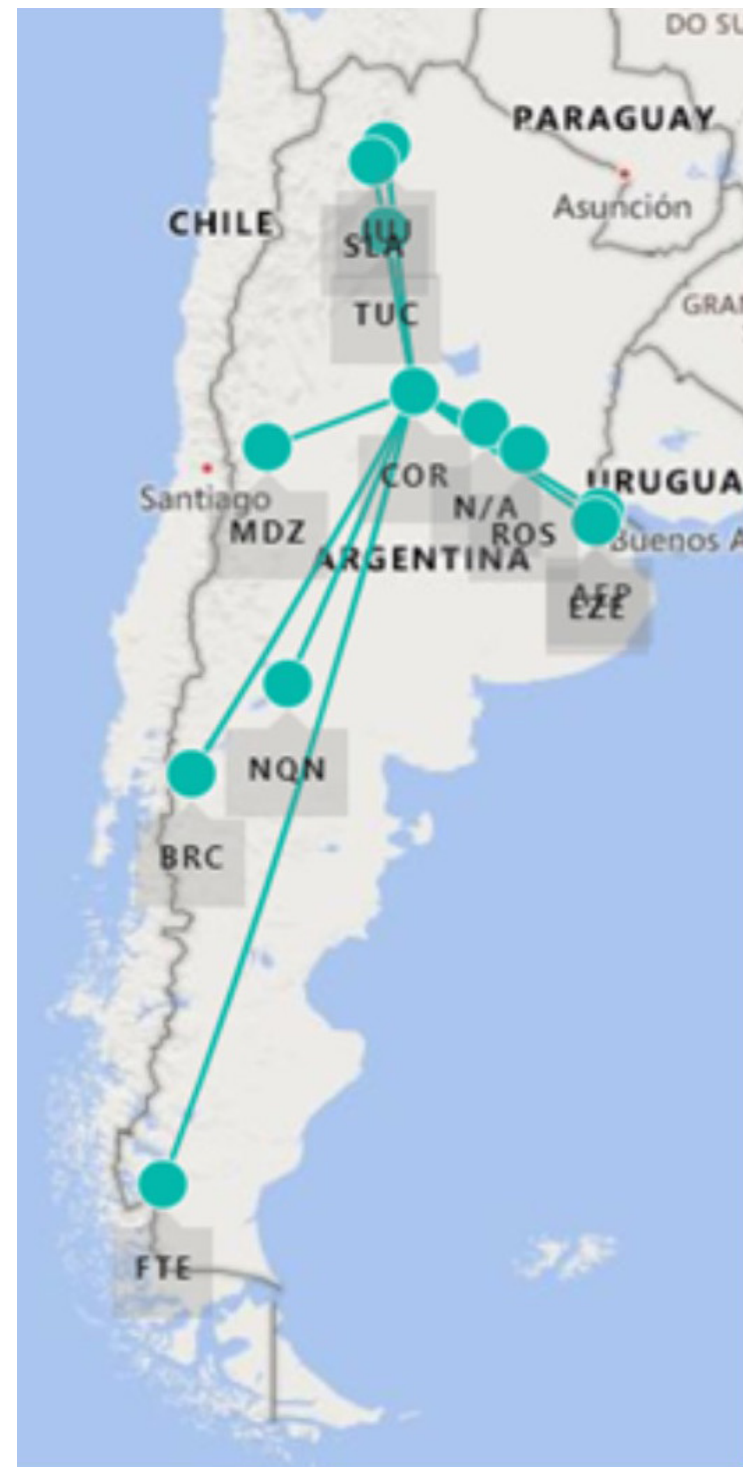

Figura 6. Rutas aéreas de cabotaje desde el Aeropuerto de Córdoba (COR). Año 2019. Fuente ANAC. 


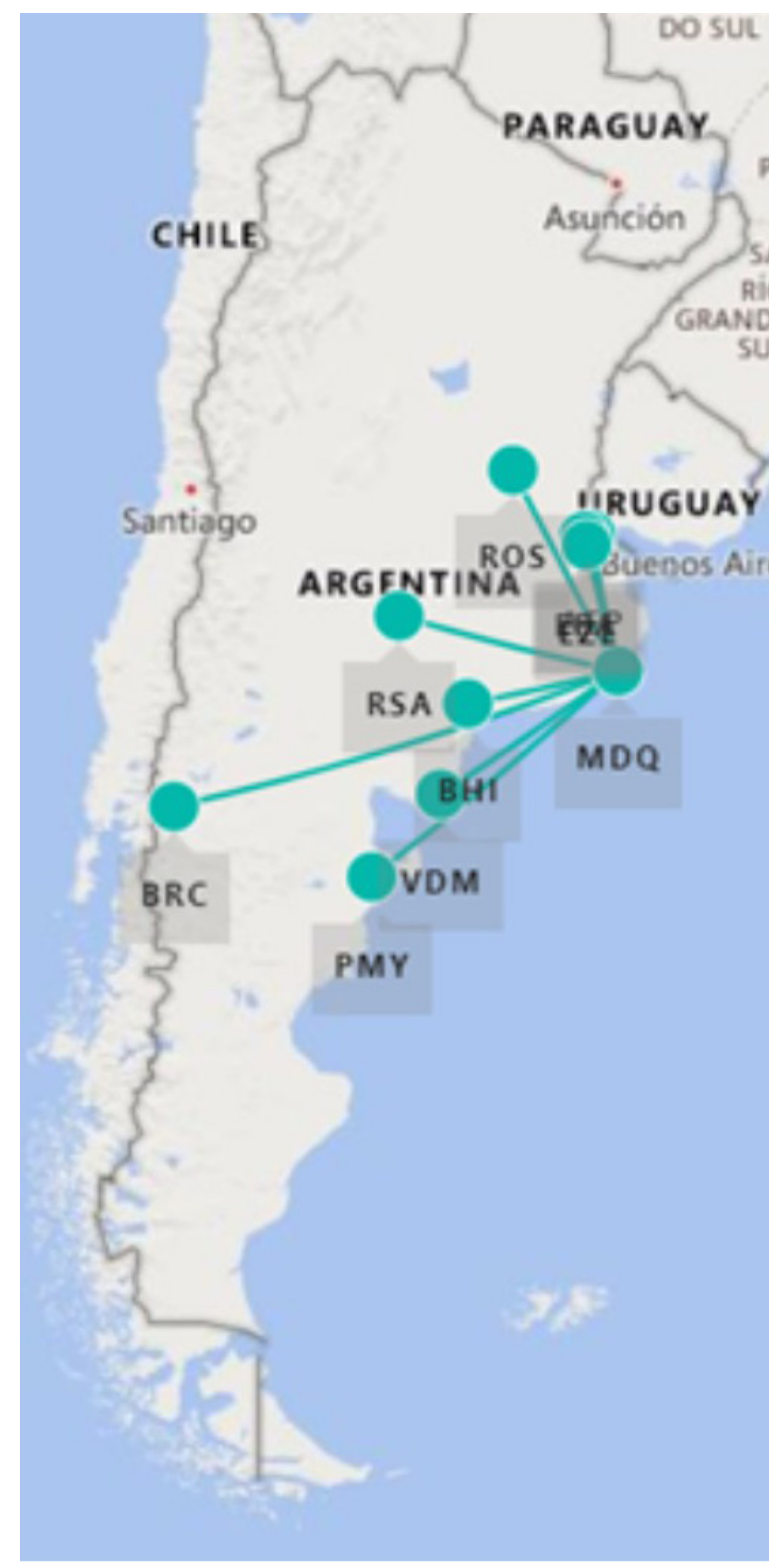

Figura 7. Rutas aéreas de cabotaje desde el Aeropuerto de Mar del Plata (MDQ). Año 2019. Fuente ANAC.

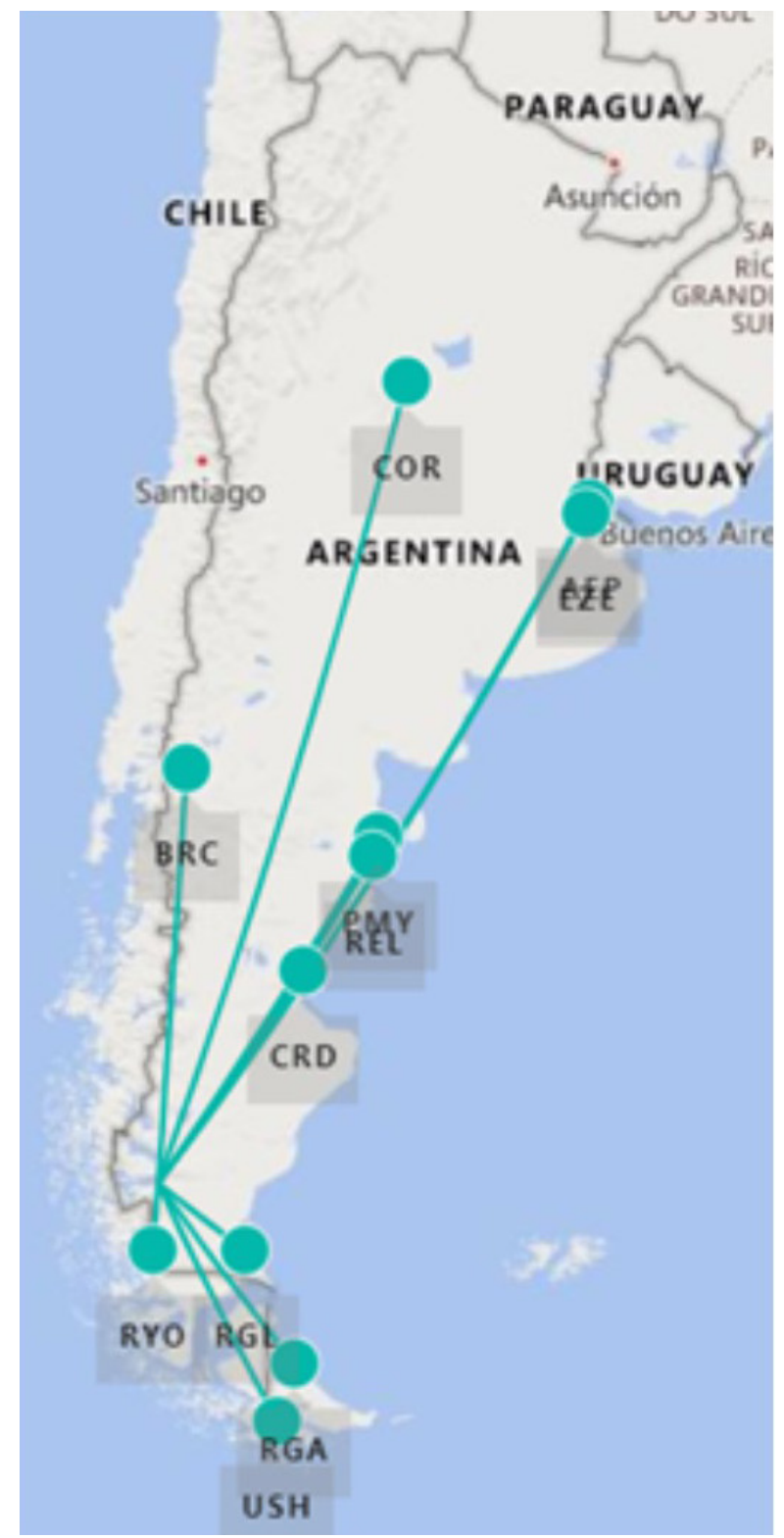

Figura 8. Rutas aéreas de cabotaje desde el Aeropuerto de Calafate (FTE). Año 2019. Fuente ANAC. 


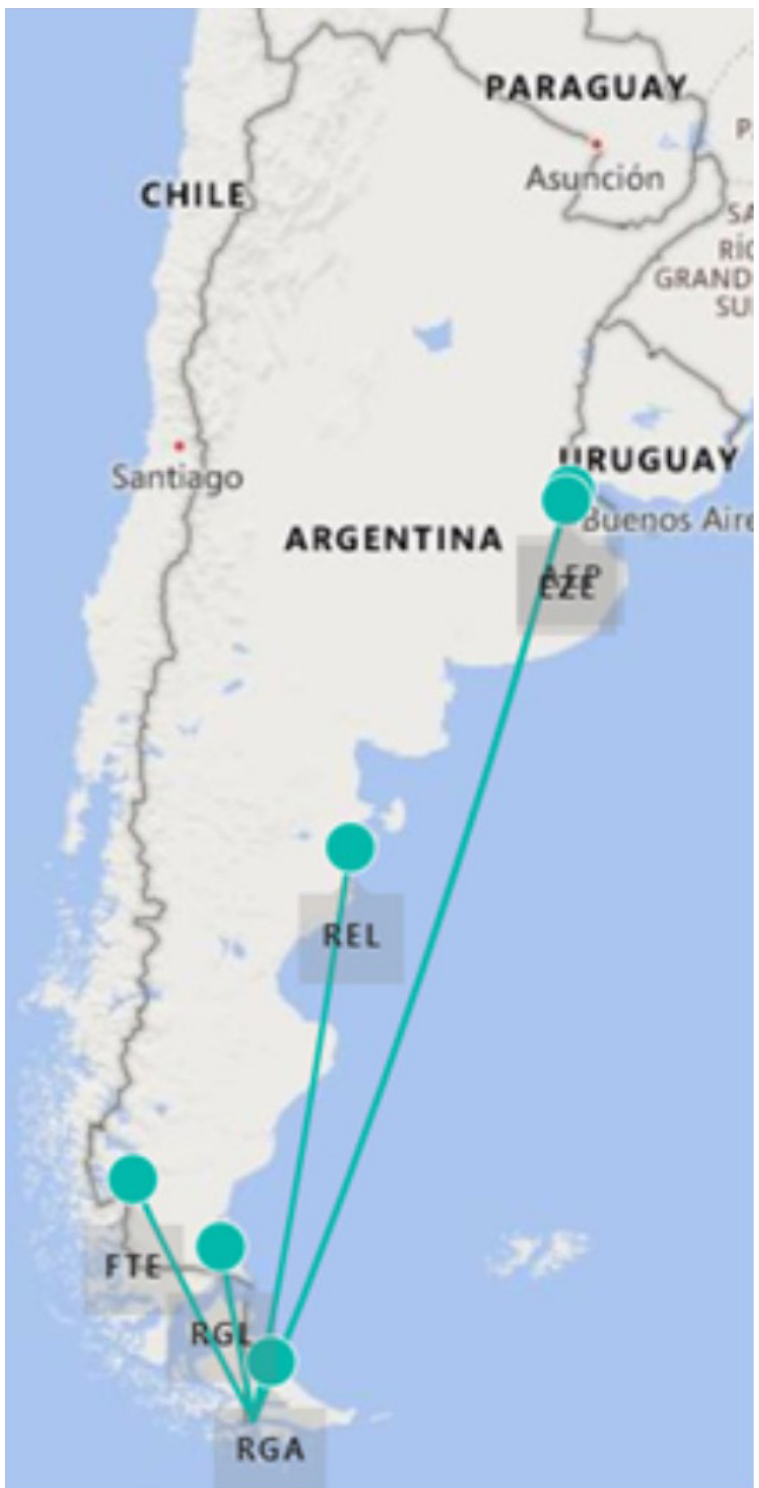

Figura 9. Rutas aéreas de cabotaje desde el Aeropuerto de Usuahia (USH). Año 2019. Fuente ANAC.

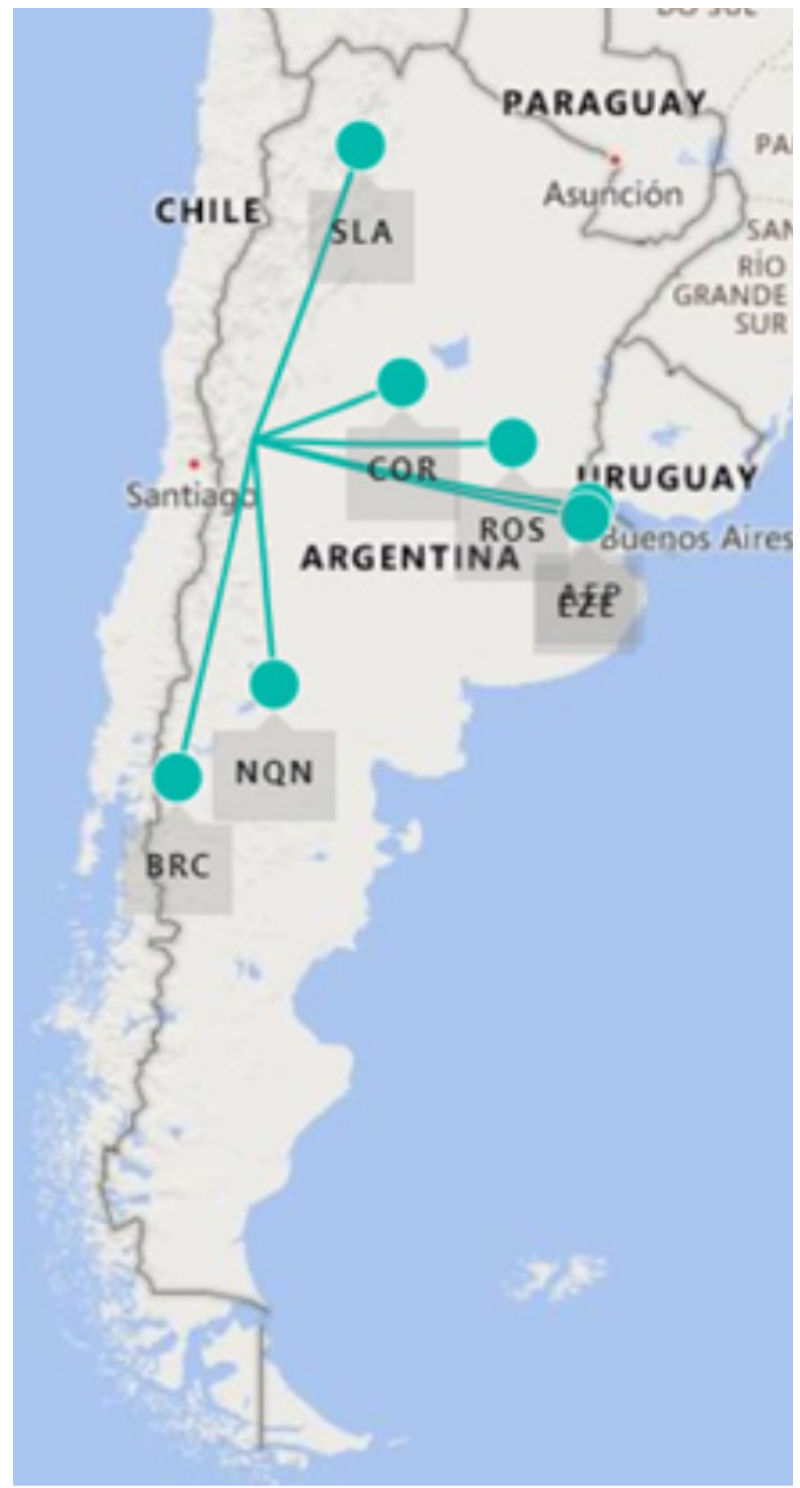

Figura 10. Rutas aéreas de cabotaje desde el Aeropuerto de Mendoza (MDZ). Año 2019. Fuente ANAC. 
La importancia de la ciudad de Buenos Aires en cuanto al turismo por Argentina se ve manifiesto en las frecuencias aéreas desde Buenos Aires hacia destinos al interior del país, como también a las principales metrópolis de la región. Sumado a ello se encuentran las numerosas líneas de transporte terrestre de larga distancia que tienen como epicentro la ciudad, y que conforman la maya de la integración física ${ }^{10}$, aunque centralizada, en términos de conectar diversas localidades del interior con la ciudad de Buenos Aires. El hecho de que Buenos Aires sobresalga del resto de los aglomerados del territorio nacional, en términos turísticos y de conectividad, tiene su correlación con la infraestructura de transporte, que presenta un diseño que se sitúa en desventaja a las regiones más alejadas del aglomerado portuario Rosario-Buenos Aires (Granato y Moncarz, 2010).

La ciudad de Buenos Aires es un destino turístico en sí mismo, pero también es un paso necesario, que funciona de eslabón dentro de un itinerario más general que incluye varios destinos turísticos de Argentina, dado el formato radial de las conectividades. Si bien otros aeropuertos dentro del territorio nacional, tales como el de Córdoba o Bariloche operan vuelos internacionales, (aspecto que facilita la descentralización en materia de transporte y conectividad, sobre todo en relación al turismo internacional), el mayor volumen sigue estando focalizado en Ciudad de Buenos Aires.

De este modo, se observa el entramado de conectividad y transporte que se presenta en una escala del territorio nacional y que permite dar luz a la aptitud del transporte turístico como factor de integración, pensado en términos de achicar distancias (Harvey, 1998), conectar localidades y ser la vía esencial para la movilidad de las personas que desean trasladarse con fines turísticos. No obstante la escala nacional, como el transporte es transversal a las diversas escalas, locales regionales e internacionales, es que a continuación se esbozará un análisis sobre la escala micro-social del transporte como factor de integración y movilidad, con un estudio de caso en la ciudad de Buenos Aires.

\section{Movilidad e integración social}

La relación entre el transporte y el turismo no solo radica desde una concepción funcional en el sentido de que es necesario el desplazamiento para llegar al destino. Además existe una asociación con la movilidad al interior del mismo destino. Es en relación a este aspecto donde se encuentran formas de trasladarse y de moverse que producen integración y otras que no lo facilitan.

En este sentido, se analizan las prácticas sociales desplegadas en las estancias turísticas y su capacidad de generar lazos o bien su neutralidad al respecto. Se concibe la integración como un proceso en el que incide la reciprocidad de prácticas entre actores en circunstancias de co-presencia, de una forma en la que estas prácticas continúan, es decir, se mantienen en el tiempo (Giddens, 1995). No se hace referencia solo a una instancia de co-presencia sino a una continuidad en esas prácticas.

El nuevo paradigma de las movilidades se acopla al análisis de los turistas que se movilizan, interactúan y se desplazan en un destino turístico. Además que contribuye a la comprensión de esos movimientos, sus significados y las experiencias de los sujetos móviles (Cresswell, 2008; Gutiérrez, 2013; Sheller y Urry, 2006)"producen y reproducen la vida social y sus formas culturales". InPor movilidad se entiende al movimiento físico 
de personas y objetos organizado por regulaciones normas y saberes y realizado a través de medios redes e infraestructuras. La movilidad no es un flujo constante, es crucial incluir las situaciones o momentos de in-movilidad (la desaceleración o detención del movimiento). De esta forma se concibe la movilidad como un elemento constitutivo de lo social y al turismo como un fenómeno en donde la movilidad es inherente a su definición y un indicador a través del cual es factible identificad su capacidad para producir integración desde una perspectiva micro-social.

Los turistas al interior de la ciudad deben realizar desplazamientos, ya sea para dirigirse hacia sitios turísticos, para visitar un museo, para ir a comer, para comprar objetos y / o souvenirs. Uno de los momentos preponderantes donde los turistas pueden, o no, interactuar con los habitantes de la ciudad es el medio de transporte.

A partir de un relevamiento de campo basado en entrevistas semi-estructuradas a turistas regionales se efectúa una categorización de prácticas turísticas en función de los diversos transportes que utilizan al interior del destino, con el fin de asociar modalidades turísticas con niveles de integración.

\section{El transporte público utilizado por turistas}

Dentro del turismo urbano de la ciudad de Buenos Aires se observa a los turistas que utilizan el subte y también las diversas líneas de colectivos. Estas situaciones, funcionales al traslado desde un lugar de origen a destino preciso, presentan características que son proclives a la interculturalidad y al intercambio entre los extranjeros turistas y los ciudadanos comunes, que a diario se trasladan desde sus hogares hasta sus lugares de trabajo y que ese viaje no implica una experiencia novedosa, como tal vez sí lo manifiestan los turistas que acuden al transporte público.

Para los residentes es una experiencia habitual vinculada a la vida rutinaria de traslado asociado a la vida productiva, laboral y estudiantil, hasta pueden considerarlo como un espacio de apropiación en el que ya saben cómo moverse, un capital de movilidad acumulado, ya saben dónde ubicarse, donde posicionar los objetos que llevan con ellos. Aun así, no tan frecuentemente observan que existen personas extranjeras y que se distinguen del resto de los pasajeros, por su forma de mirar, de moverse, de observar, por la pregunta que le hacen al chofer del colectivo, si se encuentran solos. Pero cuando se trasladan en grupo, lo más distintivo es las conversaciones en otro tono lingüístico que no es el propio del lugar, a pesar de que Buenos Aires es ya es considerada cosmopolita (Bertoncello y Troncoso, 2014:10), eso suele llamar la atención e incluso propiciar la interacción pero sobre todo por la parte anfitriona. Las preguntas frecuentes siempre ahondan sobre el lugar de origen, y suelen darse conversaciones mínimas que versan sobre los más variados y desconectados temas de los que el imaginario colectivo podría esperar que se de en un viaje de colectivo o subterráneo.

Así, estas situaciones son más proclives a generar lazos o interacciones que, aunque sean superfluas, implican un intercambio con el otro a través del cual la persona luego, guarda cierta experiencia por lo inesperado de la situación en la que se dio el encuentro.

Por lo anterior, ya sea por parte de los informantes clave como también por los relatos de los turistas más autónomos se extrae que la utilización del transporte público es un ámbito donde se promueve la interacción entre turista y residente y que en general sale de la interacción artificial que surge de las transacciones en lugares turísticos o en zonas transitadas por turistas. Esa característica también se le atribuye a la planificación e infraestructura en transporte que reconoce al sistema de transporte urbano como eficaz y funcional, como se ha observado en varios de los relatos de turistas que lo han utilizado, pero también el hecho informacional 
en el que la política turística urbana promueve la utilización de transporte público tal como se observa en el sitio web oficial del Ente de Turismo de la Ciudad de Buenos Aires.

Un aspecto novedoso es no solo la utilización del transporte público por una gran parte de los turistas que visitan la ciudad sino también el funcionamiento en sí. Se podría esperar que lo que sorprenda por parte de los turistas fuese el puente de la mujer, o Caminito, o Recoleta, o cualquier otro tipo de atractivo turístico, dada esta característica "atraer" y "destacarse": No obstante, la mayoría de los entrevistados destaca algún aspecto relacionado al transporte público de la ciudad de Buenos Aires que le llama la atención. Ya sea desde la fluidez o lo práctico que les fue adaptarse a su uso, o bien la magnitud que representa la explanada del sistema de transporte ante el desconocimiento de ello como en el caso de los uruguayos residentes en Montevideo.

El transporte es parte de la cotidianeidad de los porteños, no obstante, es utilizado por los turistas, de hecho se ofrece la "sube ${ }^{11 "}$ en los centros atención al turista de modo que el turista se convierte en parte de la cotidianeidad del porteño argentino y puede experimentar en carne propia lo que sería vivir como un argentino. El extranjero como visitante esporádico, denominado aquí turista convierte al transporte en un atractivo en sí, pero impredecible, impensado, algo novedoso que devino en atractivo al encontrarse con esa realidad instaurada en las jornadas de los habitantes de la ciudad.

Los colectivos y los subtes son elementos conductores hacia un mayor involucramiento con la cultura, hábitos y costumbres locales. Si bien requiere de un esfuerzo por parte del turista en cuanto a la adaptación y al aprender el uso, es dable destacar que no son experiencias triviales para los turistas que utilizan los transportes públicos.

Algunos turistas han mencionado el hecho de utilizar colectivo como una especie de aventura, con cierto elemento de temor por la incertidumbre de los recorridos, o de las paradas, aspectos que luego se amenizan al avanzar la fluidez en su utilización y al familiarizarse con el entramado urbano y de transporte.

El transporte es un elemento que se destaca dentro de los aspectos a mencionar sobre la ciudad, ya sea por su gran magnitud, sobre todo por parte de los turistas cuyas ciudades de residencia habitual son más pequeñas y no cuentan con un sistema de transporte tan complejo como el de CABA. En esa línea, en el colectivo de los relatos analizados se han observado menciones frecuentes sobre "lo ordenado que es el transporte". También se hizo referencia a la forma desenvuelta del turista al moverse por la ciudad, indicando lo fácil que resulta la adquisición de la tarjeta sube, por ejemplo, o cómo identifican las líneas de colectivos a través de las diversas plataformas. En muchos casos no se les preguntaba a los entrevistados especialmente por el transporte, pero emanaban de sus respuestas la alusión hacia algún aspecto de sus experiencias vinculados a ello, dado que indefectiblemente tuvieron que movilizarse y se vieron en la situación de tener que elegir algún medio de transporte. A continuación algunos fragmentos que sintetizan varias de las apreciaciones sobre el transporte:

-¿Hay algo que te haya llamado la atención sobre la ciudad?

-Los transportes, por ejemplo de acá, estoy realmente sorprendido. Me quedé sorprendido porque en San Pablo tenemos mejor transporte como más moderno 
¿entendés? Pero no funciona tan bien como el de acá. No funciona tan bien como el de acá. Tenemos subtes modernos, colectivos modernos pero no funciona tan bien como acá. El tráfico es una locura allá.

- ¿Qué es lo que más te gusta de Buenos Aires?

- Que es ordenada las cosas acá. Siento que es ordenada con el transporte, es tranquilo, es como [arborizada] la ciudad. El clima, el tiempo, me gusta. (Turista Brasileño, entrevista realizada el 19 de octubre de 2016)

- Y en el transporte público pudo hacer los trayectos tranquilamente?

- $\mathrm{Si}$, tranquila, muy bueno el transporte, esa es una de las cosas que comenté con mis amigos de Brasil, que el transporte es muy bueno, hay muchos ómnibus, el subte es rápido, el ómnibus es 24 hs., cosa que raramente hay en Brasil. Entonces... hice todo en transporte público y me encantó, el precio es bueno, entonces para mí fue óptimo. Realmente creo la ciudad de BA es para felicitarla por el transporte! (Turista brasileño, entrevista realizada el 12 de noviembre de 2016).

Es cierto que el transporte no motorizado y su relación con el turismo ha sido subestimado por ciertos estudios sobre movilidad urbana (Page, 2009:147). Sin embargo, Buenos Aires es una ciudad que desde hace varios años se ha caracterizado por la movilidad autónoma, principalmente por la utilización de bicicletas y la traza de ciclo-vías que facilitan la movilidad de ciclistas por la ciudad, en los nodos centrales. Los turistas han empezado a percatarse de ello e incluso ya utilizan las bicicletas para recorrer la ciudad ${ }^{12}$. Este tipo de transporte no motorizado si bien no genera una interacción más asidua con el residente de la ciudad como sí lo impulsa el colectivo o el subte, permite una visualización dela ciudad más vasta y un alcance más amplio, en menor tiempo.

Por lo anterior se considera un aspecto clave para tomar en consideración si es que se aborda la integración a través del turismo, dado que el mismo implica desplazamiento y conexión con un aspecto importante de la cotidianidad urbana y asimismo fue un aspecto que destacaron la mayoría de los turistas entrevistados.

\section{El transporte de uso exclusivamente turístico}

Existe otro tipo de desplazamiento que frecuentan ciertos viajeros y que son exclusivamente de uso turístico. Estos son los traslados en privado, o en servicio regular, como los denominan los guías o los agentes de viajes y se realizan en transporte tipo van o autobús y que cuentan con el servicio de guía.

Las regulares son servicios de excursiones que se realizan en vehículos del tipo "ómnibus" con capacidad hasta 50 pasajeros. Suelen ser servicios que salen todos los días, sobre todo los city-tours y las excursiones a Tigre, el resto de las excursiones puede que salgan o no diariamente dependiendo de la afluencia turística de la temporada. También se utilizan estos servicios para trasladar a los turistas desde y hacia al aeropuerto, o también hacia el show de tango o algún restaurant.

12 De hecho el mismo gobierno de la ciudad ya ha diseñado circuitos turísticos en bicicleta, además de los que ya ofrecen ciertas agencias del sector privado, que organizan tours en bicicleta, tales como "Bicicleta Naranja", "urban biking", entre otros. 
Las privadas son servicios exclusivos para un grupo de pasajeros determinado que viajan juntos, suelen propiciar un trato más personalizado entre el guía y los pasajeros, dado que son servicios que no se comparten, en cambio en las regulares casi no hay interacción con el guía.

La principal característica en términos de integración social con los residentes es que en la utilización de estos tipos de transporte privado, las oportunidades de interacción entre turistas y residentes es casi nula, lo que se corresponde con modelos turísticos de enclave. Estas modalidades se observan también en las grandes ciudades donde predominan los circuitos estereotipados y que muchas veces se asocia con la burbuja turística que mantiene aislado al turista de los residentes (Judd y Fainstein, 1999). El objetivo de ofrecer y fomentar este tipo de traslados turísticos es el brindar seguridad al turista, resguardarlo de las zonas peligrosas de la ciudad, protegerlo de los arrebatos y que sus estadías sean placentera y predecibles. Se excluye la posibilidad de que el turista pueda interactuar con un residente, dialogar, charlar, preguntar algo. Las oportunidades donde esto acontece son en sitios tales como tiendas de compras de recuerdos, restaurantes, hoteles, todos ellos espacios que se encuentran preparados para recibir turistas. Estos traslados se corresponden también con modelos de turismo segregado, donde se promueve la exclusión social, no se fomenta la identidad nacional y los turistas no mantienen contacto con la población residente (Cordero Ulate, 2006).

\section{Reflexiones finales}

Analizar el transporte a partir de las múltiples escalas permite elucidar la transversalidad de enfoques para abordarlo y comprender las configuraciones que se crean a partir de las tramas que presentan los sistemas de transporte y el sentido que le dan a los mismos los propios usuarios.

Los viajes, los desplazamientos y los medios utilizados, conducen a vislumbrar la estructura de la sociedad y a comprender la trama de los hilos conductores que conectan a las sociedades y sus culturas. A lo largo del trabajo se puede observar la forma en que el sector transporte se emplaza en el territorio, mientras que asume importantes cambios de orientación, siguiendo políticas de infraestructura turística y planificación en un contexto reactivación económica como fueron los primeros años del siglo XXI.

La conjunción entre el transporte y su funcionalidad sobre la actividad turística emerge como un elemento clave para pensar al turismo considerado como estratégico, por su facilidad de redistribuir ingresos a lo largo de todo el territorio. Más allá de ese impulso y de fomentar corredores y travesías federales, sigue predominando una concentración de las redes de transporte en Buenos Aires, aspecto que no favorece un tipo de turismo totalmente integrado ya que persisten los obstáculos en las conectividades transversales y el aislamiento de ciertas regiones.

En el plano local, las formas desestructuradas de turismo que implican viajar en medios de transporte público y perderse en el conjunto de ciudadanos que transitan cotidianamente la ciudad por sus obligaciones laborales exponen un nivel de integración social, espontáneo y alejado del mercado turístico tradicional. Las nuevas tecnologías en dispositivos, enmarcados en tiempos de globalización, contribuyen, de alguna forma, a que los sujetos móviles se encuentren cada vez más autónomos y menos dependientes del mercado y del turismo estereotipado.

De esta forma la movilidad turística se acopla a las demandas urbanas y a las tendencias contemporáneas de viajar, que responden a paradigmas flexibles y desestructurados 
de hacer turismo urbano y que facilitan situaciones de integración social a través de lazos y situaciones de interacción entre turistas y residentes. Los sistemas de transporte público en el plano local constituyen instrumentos que facilitan la integración del espacio, brindan conexiones, acercan las distancias, las personas y son proclives a producir integración socio-cultural. Pero también persisten los circuitos estructurados, armados, con itinerarios pautados y la utilización de transportes privados, que disuaden una integración genuina a través de los viajes y que se corresponden con una concepción mercantilista del turismo.

Retomando el supuesto del inicio, para pensar al turismo como factor de integración a través del transporte, se precisa de aunar las escalas y de abordar al transporte en términos de infraestructura, como un objeto de política pública y como una lente para explorar la composición de la sociedad actual. Bajo un enfoque sociológico, amplio e interdisciplinario se puede ensamblar al territorio y a los sujetos sociales para comprender las complejidades que atañen a las movilidades en general y al turismo en particular. 


\section{Q Bibliografía}

»Bertoncello, R., y Troncoso, C. (2014). La ciudad como objeto de deseo turístico: renovación urbana, cultura y turismo en Buenos Aires y Salta (Argentina). Gran Tour: Revista de Investigaciones Turísticas, 9, 4-26.

»Blanco, J. (2010). Notas sobre la relación transporte-territorio : implicancias para la planificación y una propuesta de agenda. Revista Transporte y Territorio, 3, 172-190.

"Castro, L., y Lotitto, E. (2014). Hacia un transporte interurbano de pasajeros de calidad para la equidad Índice Tablas, Gráficos y Recuadros.

»Catalano, B. (2017). Turismo e integración regional: el caso del Mercosur. In Novas fronteiras de estudos em turismo: dialogando com as Relações Internacionais (pp. 107-149). São Paulo: InMod.

»Catalano, B. (2018). Prácticas socio-culturales de los turistas: un abordajecomparativo sobre los circuitos turísticos en la ciudad de Buenos Aires. Gran Tour: Revista de Investigaciones Turísticas, 18, 40-57.

" Cordero Ulate, A. (2006). Nuevos ejes de acumulación y naturaleza. El caso del turismo. Buenos Aires: CLACSO, Consejo Latinoamericano de Ciencias Sociales.

»Cresswell, T. (2008). Constellations of mobility. Institute of English Studies, 1-36.

» Fernández Miranda, R. (2011). Viajar perdiendo el Sur. Crítica del turismo de masas en la globalización. Madrid: Libros en acción.

»Giddens, A. (1995). La constitución de la sociedad. Bases para la teoría de la estructuración. Buenos Aires: Amorrortu.

» Glick Schiller, N., y Salazar, N. B. (2013). Regimes of Mobility Across the Globe. Journal of Ethnic and Migration Studies, 39(2), 183-200.

»Granato, M. F., y Moncarz, P. (2010). Infraestructura del transporte interno en Argentina y su incidencia sobre las exportaciones provinciales. Integración y Comercio, 39-62.

»Gutiérrez, A. (2013). ¿Qué es la movilidad? Elementos para (re) construir las definiciones básicas del campo del transporte. Bitácora Urbano-Territorial, 21(2), 61-74.

» Harvey, D. (1998). La condición de la modernidad. Investigación sobre los orígenes del cambio cultural. Journal of Chemical Information and Modeling (Vol. 53). Buenos Aires: Amorrortu.

» IIRSA. (2005). Facilitación del Transporte en los Pasos de Frontera de Sudamérica. Buenos Aires.

" Judd, D. R., y Fainstein, S. S. (1999). The tourist city. New Haven: Yale University Press.

"Larsen, J., Urry, J., y Axhausen, K. (2006). Mobilities, Networks, Geographies. Hamphshire: Ashgate Publishing Limited.

»Lew, A. A., Hall, C. M., y Williams, A. M. (Eds.). (2004). A Companion to Tourism (First). Blackwell Publishing.

» MINTUR. (2011). Plan Federal Estratégico de Turismo Sustentable 2020. 
" MINTUR. (2015). Anuario Estadístico de Turismo. Buenos Aires- Argentina.

"Moufakkir, O, y Kelly, I. (2010). Tourism, progress and peace. (Omar Moufakkir, Ed.). Wallingford: $\mathrm{CABI}$.

»Oliva, M., y Schejter, C. (2006). El empleo en las ramas características del turismo en Argentina. Aportes y Transferencias, 2, 36-68.

»Page, S. (2009). Transport and tourism. Global perspectives (3rd ed.). Harlow: Pearson.

»Panosso Netto, A., y Lohmannm Guilherme. (2012). Teoría del turismo. Conceptos, modelos y sistemas. México: Trillas.

»Pastoriza, E. M., y Piglia, M. (2012). ASOCIACIONES CIVILES , EMPRESAS Y ESTADO EN LOS ORÍGENES DEL TURISMO ARGENTINO Introducción. Anuario IEHS, 27, 393-415.

"Piglia, M. (2012). En torno a los Parques Nacionales: primeras experiencias de una política turística nacional centralizada en la Argentina (1934-1950). Pasos. Revista de Turismo y Patrimonio Cultural, 10(1), 61-73.

"Piglia, M. (2014). Autos, rutas y turismo : el automóvil club argentino y el estado (1st ed.). Buenos Aires: Siglo Veintiuno Editores.

"Ramírez Vázquez, D., Osorio García, M., Arellano Hernandez, A., y Nafarrate Torres, J. (2013). El turismo desde el pensamiento sistémico. Investigaciones Turísticas, 5, 1-28.

»Salazar, N. B. (2006). Antropología del turismo en países en desarrollo: Análisis crítico de las culturas, poderes e identidades generados por el turismo. Tabula Rasa: Revista de Humanidades, 5, 99-128.

"Sánchez, J. (2017). El mercado doméstico de transporte interurbano de pasajeros en Argentina. Buenos Aires.

» Schenkel, E., y García, F. A. (2015). La política turística y la intervención del Estado. El caso de Argentina. Perfiles Latinoamericanostinoamericanos, 23(46), 197-221.

"Schluter, R. (2003). Turismo en Argentina : del balneario al campo. Buenos Aires: Centro Inv. y Est. turisticos.

"SECTUR. (2005). Plan Federal Estratégico de Turismo Sustentable 2016.

"Sheller, M., y Urry, J. (2006). The new mobilities paradigm. Environment and Planning A, 38(2), 207-226. Retrieved from http://epn.sagepub.com/lookup/ doi/10.1068/a37268

»Smith, V. (1989). Anfitriones e invitados. Antropología del turismo. Madrid: Endymion.

» Tottino, L. I. (2015). ¿Más trabajo, mejor trabajo? El caso de los trabajadores y las trabajadoras de las agencias de viajes de ciudad de Buenos Aires. Universidad de Buenos Aires. Facultad de Ciencias sociales. Tesis de Maestría en ciencias sociales del trabajo".

» Turner, L., y Ash, J. (1991). La horda dorada. El turismo internacional y la periferia del placer. Madrid: Endymion.

»UNWTO y UNESCO. (2015). Declaración de Siem Reap sobre turismo y cultura : Construyendo un nuevo modelo de cooperación. Camboya.

»Urry, J., y Lash, S. (1998). Economía de signos y espacios. Sobre el capitalismo de la 
posorganización. Buenos Aires: Amorrortu.

»Vellas, F. (2004). Economía y política del turismo internacional. Madrid: Síntesis.

»Ventura-Dias, V. (2011). El turismo, su cadena productiva y el desarrollo incluyente en América Latina : los casos de Brasil y México, 81.

»Wallingre, N. (2010). Responsabilidad del transporte aéreo en la dinámica territorial para el desarrollo del turismo argentino. El aporte pendiente. Revista Transporte y Territorio, 2, 99-120.

»Zunino Singh, D. (2017). Términos clave para los estudios de movilidad en América Latina. Buenos Aires: Biblos.

\section{Bárbara Catalano / catalano81@gmail.com}

Becaria posdoctoral CONICET, con asiento en el Instituto de Investigaciones Gino Germani. Doctora en Ciencias Sociales (UBA), Mg en Procesos de Integración Regional y Mercosur (UBA) y Lic. En Turismo (USAL). Docente de grado y posgrado UMET/ UBA y coordinadora del Grupo de Estudios sobre Turismo y Sociedad del IIGG. 